\title{
Vulnerability Aspects That Hinder Tuberculosis Healing According To The Perspective Of Patients And Healthcare Managers
}

\begin{abstract}
Sheylla Nadjane Batista Lacerda1, 2, Tânia Maria Ribeiro Monteiro de Figueiredo³, Fernanda Darliane Tavares de Luna ${ }^{3}$, Rayrla Cristina de Abreu Temoteo 2,3, Edwirde Luiz Silva ${ }^{3}$, Luiz Carlos de Abreu ${ }^{1}$, Ligia Ajaime Azzalis ${ }^{5}$, Vitor Engrácia Valenti ${ }^{4}$, Virginia Berlanga Campos Junqueira ${ }^{4}$, Fernando Luiz Affonso Fonseca ${ }^{1,5}$
\end{abstract}

\section{Abstract}

Introduction: Tuberculosis is a major public health condition worldwide. The partnership between Healthcare Services and the patient is the gold standard for a successful healing outcome and a reduction in the harm the disease causes to patients and society in general.

Objective: To analyze the vulnerability aspects that make tuberculosis healing difficult according to the perspective of patients and public healthcare managers.

Methods: This is a descriptive study conducted in the year 2013 in Cajazeiras, a town located in the state of Paraíba in the northeastern region of Brazil. The study population was composed of 4 healthcare managers and 29 patients with confirmed tuberculosis diagnosis. In order to gather the sample of tuberculosis patients, a search on the Information System on Diseases of Compulsory Declaration (SINAN, in the Portuguese abbreviation) was run.

Results: All patients had fixed addresses. Among these individuals, a total of 12 were of the male sex, $13.6 \%$ were smokers, $77.3 \%$ were alcohol-free and $13.6 \%$ were frequent alcohol consumers. In addition to that, $72.7 \%$ of the patients received no public financial support of any sort. As to coping with the disease, $54.5 \%$ declared no difficulty at all, $22.7 \%$ found it very difficult, $18.2 \%$ reported it was somewhat difficult and $4.5 \%$ stated it was extremely difficult. Concerning family income, $68.0 \%$ lived on up to two minimum wages.
1 Faculdade de Medicina do ABC, Santo André, SP, Brazil.

2 Faculdade Santa Maria, Cajazeiras, PB, Brazil.

3 Universidade Estadual da Paraíba, Paraíba, PB, Brazil.

4 Universidade Estadual Paulista (UNESP), Marilia, SP, Brazil.

5 Universidade Federal de São Paulo (UNIFESP), Diadema, SP, Brazil.

Contact information:

Sheylla Nadjane Batista Lacerda.

” sheyllabatista@bol.com.br

Keywords

Patient; health manager; tuberculosis; vulnerability 
Final considerations: The findings in the current study revealed the vulnerability condition upon which tuberculosis patients live, highlighting the social exclusion of this population with their low educational level, their low-income status, their poverty condition and their difficulty in understanding their basic needs, such as the necessity of a well-balanced diet to prevent the adverse effects caused by the drugs during the treatment. Managers identified social stigma, prejudice, denial of the disease with a resultant resistance to treatment, street-dwelling individuals and drinking and smoking habits as major difficulties for tuberculosis control in the city. It is quite clear that the managers approach the universe of vulnerability within its three inseparable dimensions: individual, social and programmatic. A better understanding of the real needs of tuberculosis patients as well as the prioritization of the disease are of utmost importance in the municipal public health agenda, which is based on a higher involvement of managers in the participation, discussion and definition of the application of resources for the disease control and a public health policy that encompasses tuberculosis social issues.

\section{Introduction}

Although incidence and death rates have been declining over the past few years, tuberculosis (TB) is still a major public health condition worldwide [1]. Considering that it is estimated that one third of the world population is infected by the Mycobacterium tuberculosis, the main causal infectious agent of tuberculosis in humans, the risk of active TB development in this group is present $[2,3,4]$. In 2012 nearly 8.6 million people developed the disease all over the world [5].

In Brazil there are around 57 million infected individuals, a number that ranks the nation as 16th within the group of 22 countries that concentrate $80 \%$ of global TB cases [2, 4-6]. In 2013 a total of 71,123 new cases were diagnosed in the country, representing an incidence coefficient of 35.4/100,000 inhabitants [6]. All over the state of Paraíba, this coefficient was of 29.3 cases in the year 2012, and only in Cajazeiras the coefficient was of 29.1 cases in the same year [7], a fact that classifies the incidence of tuberculosis in this population as intermediary ( $>20 / 100$ thousand $<50 / 100$ thousand) [8] and puts the city at the top of the priority list of actions to be taken by the Ministry of Health in Brazil.

In order to control TB, it is of extreme importance to reduce the number of infected individuals, which is only made possible by treating the notified cases. As a public health guideline, the World Health Organization (WHO) recommends strategic measures such as managing TB control in compliance with Primary Attention to Health (PAH), an active search for respiratory symptomatic subjects and the use of Directly Observed Treatment (DOT) [3, 9, 10].

Therefore, interventions for TB control must be based on the social and demographic profile of the population [11, 12]. The Ministry of Health in Brazil sets goals of healing bacilliferous TB cases to $85 \%$ and a reduction in treatment abandonment to rates lower than 5\%. 
In the universe of vulnerabilities, all constituent elements of life in society regarding the most basic needs for its development, such as dwelling, leisure, information and healthcare services among others, interrelate in order to express individual and collective potentials for illness and non-illness factors as well as the management of health adverse events $[13,14]$.

The individual dimension focuses on the knowledge of the harm and conducts that give space for the infection onset. It is determined by cognitive (access to information, awareness of susceptibility and effectiveness of prevention methods), behavioral (will and capacity of changing behaviors that lead to susceptibility) and social (access to resources and the capacity to adopt protective behaviors) conditions. The programmatic dimension refers to assets, inputs and services provided to the general population by means of public health policies [15].

The duet healthcare managers and patients is of paramount importance for TB treatment success. Health services cannot be limited by restrictions in the practices of control program. Managers have to be involved with the disease control by investing in actions that support prevention and treatment of the condition and puts it as a top priority in the health agenda of the municipality [10].

Therefore, considering that the patient may find himself in individual, social and/or programmatic vulnerability conditions, the current study aims to analyze the vulnerability aspects that hinder tuberculosis healing according to the perspective of patients and healthcare managers.

\section{Methods}

This is a descriptive study with a questionnaire on the evaluation of healthcare services and a quantiqualitative approach. It was conducted in the year 2013 in reference to the period between January 2012 and July 2013.
Notification for tuberculosis is mandatory. Therefore, the diagnosed patients had previously been notified to the Information System on Diseases of Compulsory Declaration (SINAN) during the period mentioned above. A total of 29 cases were notified from which 22 were included in the study.

Among the exclusion criteria were individuals who could not be located, those with communication difficulties, prison inmates, people with high alcohol intake which disrupted coherence in communication or those who refused to take part in the study $(n=07)$.

In the quantitative data analysis the socio-demographic profiles as well as the difficulties met to obtain the disease diagnosis were developed. Factors like the time to access results of exams and the onset of treatment were taken into consideration. The data were described in tables, with frequencies and measures of dispersion of socio-economic variables and the establishment of epidemiological indicators.

Only one evaluation was performed among the four healthcare managers involved in the Municipal Tuberculosis Control Program, namely the Municipal Health Secretary, with a degree in physical therapy, the Epidemiology Surveillance Coordinator, the Basic Care Coordinator and the Coordinator of the Municipal Tuberculosis Control Program (MTCP). The last three professionals have a degree in nursing.

The data were collected during the months of August and September of 2013 through a semistructured interview performed with patients at their homes and/or healthcare units and with managers of the Municipal Health Department. The following guiding question was asked for the sake of qualitative data collection: "What difficulties do TB patients meet when it comes to healing from the disease?" The interview was digitally recorded so that all participants' statements could be fully registered and subsequently transcribed verbatim in Portuguese. Adaptations were made necessary 
during the translation process into the English language for the sake of a meaningful comprehension. In order to ensure anonymity, all participants were identified by the letter $G$ (from the word "gestor", i.e., "manager" in Portuguese) followed by a number which indicated the interview order.

The analysis of content (AC) proposed by Laurence Bardin [16] was used to analyze qualitative data. The methodology consists of a series of techniques for communication analysis so that the description of the message contents can be obtained, which are indicators that allow for the knowledge inference related to the conditions of production (emission)/reception of these messages. Themecategory analysis was the methodology of choice from which the category "discourse analysis" was extracted.

The study was approved by the Human Research Ethics Committee from Faculdade de Medicina do ABC (ABC Medical School) under CAAE protocol no. 11784313.1.0000.0082.

\section{Results and discussion}

\section{Quantitative Approach}

The sample was constituted of 22 participants. None of them was homeless, $13.6 \%$ were smokers, $77.3 \%$ were alcohol-free individuals, $13.6 \%$ frequently consumed alcohol and/or other kinds of illicit drugs and 9.1\% occasionally consumed alcohol.

When asked about the difficulties they met dealing with the disease and the treatment, 54.5\% of the patients declared no difficulty at all, $22.7 \%$ found it very difficult, $18.2 \%$ reported it was somewhat difficult and $4.5 \%$ stated it was extremely difficult. Adversities were always related to the collateral effects caused by the medication and the long-term and nonstop treatment, which lasts at least 6 months. The effects that were most mentioned by the interviewees were nausea and dry mouth, gastric intolerance, a variety of cutaneous manifestations, jaundice and joint pains.
Regarding the social context of tuberculosis, the study revealed that men at an economically productive age were the ones who had the highest rate of the disease. This is a fact that brings direct and relevant social repercussions once TB patients become too debilitated to work, which prevents them from providing financial support for their families.

As seen in Table 1, the number of male TB patients is higher and their educational level is lower. The very opposite can be observed when it comes to females: the number of patients is lower and their educational level is higher.

Table 1. Socio-demographic data of TB patients, Cajazeiras-PB-Brazil, 2012-2013.

\begin{tabular}{|c|c|c|}
\hline \multirow{2}{*}{ Variables } & \multicolumn{2}{|c|}{$2012-2013$} \\
\hline & N & $\%$ \\
\hline \multicolumn{3}{|l|}{ Sex } \\
\hline Male & 12 & 54.5 \\
\hline Female & 10 & 45.5 \\
\hline \multicolumn{3}{|l|}{ Age Group } \\
\hline 18 to 25 & 01 & 4.5 \\
\hline 26 to 49 years & 15 & 68.2 \\
\hline 50 to 59 & 02 & 9.1 \\
\hline Over 60 years & 04 & 18.2 \\
\hline \multicolumn{3}{|l|}{ Education Background } \\
\hline No education & 02 - Male & 9.1 \\
\hline \multirow{2}{*}{ From 1 to 3 years of study } & 03 - Male & 18.2 \\
\hline & 01 - Female & \\
\hline \multirow{2}{*}{ From 4 to 7 years of study } & 05 - Male & 36.4 \\
\hline & 03 - Female & \\
\hline \multirow{2}{*}{ From 8 to 14 years of study } & 01 - Male & 18.2 \\
\hline & 03 - Female & \\
\hline \multirow{2}{*}{$\begin{array}{l}\text { From } 15 \text { or more years of } \\
\text { study }\end{array}$} & 01 - Male & 13.6 \\
\hline & 02 - Female & \\
\hline Graduate students & 01 - Female & 4.5 \\
\hline \multicolumn{3}{|l|}{ Family income } \\
\hline $\begin{array}{l}\text { From } 1 / 2 \text { to } 1 \text { minimum } \\
\text { wage }\end{array}$ & 06 & 27.3 \\
\hline $\begin{array}{l}\text { From } 1 \text { to } 2 \text { minimum } \\
\text { wages }\end{array}$ & 09 & 40.9 \\
\hline $\begin{array}{l}\text { From } 3 \text { to } 5 \text { minimum } \\
\text { wages }\end{array}$ & 05 & 22.7 \\
\hline $\begin{array}{l}\text { From } 5 \text { to } 10 \text { minimum } \\
\text { wages }\end{array}$ & 02 & 9.1 \\
\hline
\end{tabular}




\section{INTERNATIONAL ARCHIVES OF MEDICINE \\ Section: Global Health \& Health Policy \\ ISSN: 1755-7682}

Vol. 8 No. 48

doi: $10.3823 / 1647$

Tb patients who declared income as

Enough for survival 08

Barely enough

07

07

07

36.4

31.8

Not enough

31.8

Number of people per household

\begin{tabular}{|l|l|c|}
\hline 01 Person & 01 & 4.5 \\
\hline 02 to 03 People & 02 & 9.1 \\
\hline 04 to 05 People & 15 & 68.2 \\
\hline 06 to 07 People & 03 & 13.6 \\
\hline 08 to 09 People & 01 & 4.5 \\
\hline Total & 22 & \\
\hline
\end{tabular}

Besides the low educational background, this population of sick individuals live on a low income, which, as far as they are concerned, is enough for their survival.

Table 2 compares managers' and TB patients' statements. The findings reveal that $72.7 \%$ of the patients received no financial support of any sort from the municipality. When asked if public funding was available for this purpose, $25.0 \%$ of the managers did not know or did not answer the question. Since $68.2 \%$ of the patients have a monthly income of up to 2 minimum wages and they have to share their

Table 2. Socio-economic incentive provided by the municipality and the period of time patients took to undergo exams and receive TB diagnosis in Cajazeiras, Paraíba, Brazil, 2012-2013.

\begin{tabular}{|c|c|c|c|c|c|}
\hline \multicolumn{3}{|c|}{ Variables - Managers } & \multicolumn{3}{|c|}{ Variables - Patients } \\
\hline Social Incentive & $\mathrm{N}$ & $\%$ & Social Incentive & N & $\%$ \\
\hline Incentive is available & 03 & 75.0 & Claim not to receive & 16 & 72.7 \\
\hline \multirow[t]{2}{*}{ Don't know/Didn't answer } & 01 & 25.0 & Claim to receive & 04 & 18.2 \\
\hline & & & Claim to occasionally receive & 02 & 9.1 \\
\hline Bacilloscopy result & N & $\%$ & Bacilloscopy result & N & $\%$ \\
\hline$<7$ days & 01 & 25.0 & $\leq 7$ days & 15 & 68.2 \\
\hline$\geq 7$ days & 02 & 50.0 & $>7 \leq 15$ days & 04 & 18.2 \\
\hline \multirow[t]{2}{*}{ Don't know/Didn't answer } & 01 & 25.0 & $>15 \leq 30$ days & 01 & 4.5 \\
\hline & & & Não sabe/Não respondeu & 02 & 9,1 \\
\hline Bacilloscopy result & N & $\%$ & Bacilloscopy result & N & $\%$ \\
\hline$<7$ days & 01 & 25.0 & $\leq 7$ days & 15 & 68.2 \\
\hline$\geq 7$ days & 02 & 50.0 & $>7 \leq 15$ days & 04 & 18.2 \\
\hline Don't know/Didn't answer & 01 & 25.0 & $>15 \leq 30$ days & 01 & 4.5 \\
\hline X-ray result & N & $\%$ & $\mathrm{X}$-ray result & $\mathrm{N}$ & $\%$ \\
\hline$\leq 1$ day & 02 & 50.0 & $\leq 1$ day & 16 & 72.7 \\
\hline 15 days & 01 & 25.0 & 15 days & 03 & 13.6 \\
\hline \multirow[t]{8}{*}{ Don't know/Didn't answer } & 01 & 25.0 & Don't know/Didn't answer & 03 & 13.6 \\
\hline & & & $\begin{array}{l}\text { Time elapsed between signs/ } \\
\text { symptoms onset and TB } \\
\text { diagnosis }\end{array}$ & N & $\%$ \\
\hline & & & $\leq 7$ days & 02 & 9.1 \\
\hline & & & $>7 \leq 15$ days & 03 & 13.6 \\
\hline & & & $>15 \leq 30$ days & 04 & 18.2 \\
\hline & & & $>30 \leq 60$ days & 07 & 32.0 \\
\hline & & & $>60 \leq 270$ days & 05 & 22.6 \\
\hline & & & $>1$ year & 01 & 4.5 \\
\hline Total & 04 & & & 22 & \\
\hline
\end{tabular}


earnings with 4 or 5 household members, public financial support is advisable not only to stimulate patient adherence to medication treatment, but also to help reduce social issues. Furthermore, many times a special diet is required due to the debilitation caused by the disease and the adverse effects generated by the therapeutic treatment. Living on a low income, patients cannot afford this cost; therefore, public contributions like the Brazilian program "Cesta Básica", which involves the distribution of basic food products to low income families, are very helpful in such cases.

These data show the poor social situation in which TB patients live. Financial support would be of great relevance to decrease social issues, to help treatment adherence and to reduce the gastric discomfort caused by the medication, which demands a regimen of a proper diet that provides patients with more comfort and improves their well-being.

Tuberculosis is an infectious disease, and it is of the utmost importance that the patient be diagnosed during the first days after the onset of the signs and symptoms, start the treatment and break the chain of transmission. According to patients' reports, after the onset of the signs and symptoms, 32\% waited from 30 to 60 days to receive the positive diagnosis for tuberculosis, 9.1\% waited until 7 days for the diagnosis and 4.5\% were diagnosed after one year of suffering with the signs and symptoms of the disease (Table 2). While the diagnosis was not established, these patients unwittingly spread the bacillus to the general population.
The National Tuberculosis Control Program (NTCP) recommends that bacilloscopy results should be delivered to patients within 48 hours or less, and in case they are positive, patients should immediately start the treatment process. Among the managers that participated in the TB control actions in the municipality, 50\% declared that patients waited over 7 days to receive the bacilloscopy result. As to the patients included in this study, 68.2\% received the result within 7 days, $18.2 \%$ received it between 7 and 15 days and $4.5 \%$ had it between 15 and 30 days (Table 2). Therefore, since the beginning of treatment is often delayed according to the data supplied above, TB control becomes a much more challenging issue.

Concerning the period of time to receive X-ray results, $25 \%$ of the managers informed that results were released to TB patients within 15 days, $72.7 \%$ of the patients reported receiving the result in 1 day and $13.6 \%$ said they received it in 15 days (Table 2). The NTCP recommends that $X$-ray results be delivered to TB patients in 24 hours.

The data show that $23.8 \%$ of the studied subjects were diagnosed at hospitals, characterizing a delayed diagnosis of the disease. $38.1 \%$ of the cases were diagnosed at Family Health Strategy units, demonstrating the low rate of active search for respiratory symptomatic patients for the early diagnosis of tuberculosis. $28.6 \%$ of the patients were diagnosed in private medical offices. $9.5 \%$ were diagnosed at outpatient clinics.

Framework 1. Estimate statement of TB cases in the municipality of Cajazeiras/Paraíba/Brazil, 2013.

\begin{tabular}{|c|c|c|c|c|c|c|c|}
\hline Municipality & $\begin{array}{l}\text { Population } \\
\text { (IBGE, } \\
\text { 2010) }\end{array}$ & $\begin{array}{c}1 \% \text { of } \\
\text { respiratory } \\
\text { symptomatic } \\
\text { cases }\end{array}$ & $\begin{array}{l}4 \% \text { of the } \\
\text { RSP will } \\
\text { have TB }\end{array}$ & $\begin{array}{l}\text { New } \\
\text { diagnosed } \\
\text { cases }\end{array}$ & $\begin{array}{l}20 \\
\text { Expected } \\
\text { TB cases }\end{array}$ & $\begin{array}{l}\text { Absolute value } \\
\quad \text { of } \\
\text { sub-notification }\end{array}$ & $\begin{array}{c}\text { Sub-notification } \\
\text { rate }\end{array}$ \\
\hline Cajazeiras & $\begin{array}{c}58,446 \\
\text { inhabitants }\end{array}$ & 584 & 23 & $\begin{array}{c}192 \\
(2001-2010)\end{array}$ & $\begin{array}{c}23 \times 10= \\
230\end{array}$ & 38 & $16.52 \%$ \\
\hline \multicolumn{4}{|c|}{$\begin{array}{l}\text { Source: Estimate based on TB control guidelines and } \\
\text { recommendations from Brazil (Ministry of Health, } \\
\text { 2011). [22] }\end{array}$} & \multicolumn{3}{|c|}{ *RSP $=$ Respiratory Symptomatic Patients } & \\
\hline
\end{tabular}


Concerning tuberculosis in the municipal agenda, $75 \%$ of the managers reported their non-participation in the discussion and definition of financial investment policies for TB control, 25\% stated that they occasionally participated. When asked about the application of the municipality's own resources for the control of tuberculosis, $50 \%$ of the managers answered that they were of aware of the municipality's participation whereas 50\% reported that they did not know or preferred not to answer the question.

Among the interviewed managers, 50\% declared that the municipality has a health policy focused on the tuberculosis patient that abandons the treatment; $50 \%$ stated they did not know or preferred not to answer.

Within this context, it can be observed that despite being affected by an infectious disease of great magnitude, the studied patients do not fully understand an individual's basic needs to live a healthy life, and thus they become outcasts in their own society. The World Health Organization (WHO) defines health as "a state of complete physical, mental and social well-being and not merely the absence of disease or infirmity".

What the current study clearly shows is the absence of health in this population and their social exclusion. Owing to their low-income status and their low educational level, these individuals cannot visualize the importance of having access to dignified housing and employment, leisure, information, proper nutrition and healthcare services. Since they live in extreme poverty, they are susceptible to all sorts of diseases which lead them to a state of individual and social vulnerability.

A third kind of vulnerability, besides the individual and social, is also observed, namely the programmatic vulnerability. It stands out whenever the fragility of healthcare managers comes up in the planning of actions for tuberculosis control in the municipality involving basic health care services.

\section{Qualitative Approach}

The following guiding question was asked: "What difficulties do TB patients meet when it comes to healing from the disease?"

After the analysis of the answers provided by the participants, four theme categories were identified: stigmas, denial of the disease, resistance to treatment and lifestyle.

\section{Category 1 - Stigmas}

All managers reported stigma as a huge barrier to be brought down. They mentioned the history of the disease, marked by prejudice and social segregation as seen in the statements below:

The greatest difficulty patients have to face is the stigma the disease carries ....

One of the difficulties is the stigma within the disease ... the prejudice against the disease...

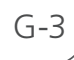

...there is a myth concerning the disease once it used to be untreatable for so many years...

$\mathrm{G}-4$.

Patients are also segregated within their own families, and this segregation comes from, according to the managers, the stigma that surrounds the disease shown in the following statements:

..before knowing about the disease, all family members interact normally. Then, when they find out one of the members has the disease, segregation takes place. 'That' stigma comes out...

Managers see the stigma as a triggering factor for other difficulties that slow down TB healing, such as denial of the disease and resistance to start the drug-based treatment, illustrated in the statements below: 
...the acceptance of the disease, then the stigma the disease carries; it all makes accepting the treatment so much more difficult...

$\mathrm{G}-1$

...sometimes they even feel ashamed of going to the unit given the fact other people might see them there...

As this is a disease surrounded by stigmas and myths, people always think they will never heal despite the treatment...

In this perspective, TB is marked by the persistent stigmatization of patients with their resultant isolation, which constitutes a major obstacle to the disease control. The fact is, tuberculosis is a healable disease today, so it makes no sense that it is so stigmatized [17].

Therefore, tuberculosis control programs face serious issues regarding their effectiveness due to the harmful effects the stigma causes to the society even today [18].

The stereotyped conception observed in the way our society unconsciously and jointly deals with TB patients strongly represents the stigmatization process of the disease and the patient [17]. Thus, meanings and images are built according to personal daily experiences and are disseminated by the news media, which facilitate the creation of a common reality for this social group [19] and end up strengthening not only the vulnerability dimensions TB patients have to face regarding the acceptance of the disease but also of the beginning of the treatment.

Issues related to attitudes and prejudice, fear of the stigma and discrimination among family members, friends and neighbors can also be observed. Such matters lead patients to restrict interpersonal relationships with family and friends, therefore changing their habits and lifestyles [20].
Having these relationships scarred by the stigma and prejudice towards the disease, some of the patients choose to abandon the treatment, a fact that brings out serious consequences like multidrug resistance or even death [21].

The society-related stigma is reinforced by the lack of knowledge the general population has on tuberculosis. Fallacies and myths, passed from generation to generation and so far from reality, make this stigma a limiting factor for the diagnosis and control of the disease [21].

The imaginary reality of the TB patient, ranging from something that is socially considered odd and abnormal and/or immoral and pathological, is topped with feelings of non-acceptance of the disease by other people and pushes them into a sphere of stigma and prejudice [22]. The scenario described above interconnects individual and social vulnerability aspects, which makes the treatment continuity and the consequent disease healing harder to be achieved.

Social aspects of the vulnerability analysis focus on individual vulnerability contexts such as gender, racial and ethnic relations among generations, stigmatization processes and the systematic discrimination of rights. At individual level, family, friends and professional relations along with social support networks are highlighted [23]. These last mentioned aspects of vulnerability are explicit in the described reality.

Within this context, the stigma that follows tuberculosis strengthens both the individual and the social dimensions of the vulnerabilities of these patients, along with the programmatic vulnerability, and makes the healing of the disease harder and harder.

\section{Category 2 - Denial of the Disease}

Managers mentioned denial as a barrier to the cure of the disease as exemplified in the statements below: 
I think the major difficulty TB patients have to face in our municipality is the disease denial...

...the denial process that precedes the acceptance of the disease makes everything more difficult...

One of the managers referred to the denial of the disease as one of the reasons for a delayed diagnosis. An early diagnosis is essential for a successful treatment outcome; therefore, once it is delayed, it will negatively affect the healing process:

...their difficulty to look for help starts from the delayed diagnosis.

Although there are many reasons that lead people not to seek medical assistance, the stigma the disease carries is considered as one of the most relevant factors. When compared, patients who already underwent the treatment tend to overcome or properly deal with the stigma barrier more easily than those who did not because of the stigmatization fear [18]. Not seeking medical assistance falls into the category of individual vulnerability, which may cause the aggravation of the condition with a resultant dissemination of the bacilli among the general population.

Non-acceptance of the disease can be understood as individuals who do not see themselves as patients and hide their condition from others. It results in frequent abandonment of the treatment, promoting a critical TB epidemiological situation in many scenarios [24].

Many TB patients are concerned about hiding their diagnosis from co-workers, for example, in order to avoid embarrassing situations or even exposing their already so fragile aspect to these colleagues [20]. This also represents a factor of individual vulnerability once the disease limits or hinders patients' relations in their work environment or in society as a whole.

However, the non-support from family members complies with the fear patients experience when it comes to job stability. The idea of being dismissed from work or being on a medical leave of absence explains this fear and their resistance in seeking diagnostic confirmation, which end up becoming an obstacle for the treatment [20].

A probable explanation for the hiding of TB diagnosis lies in the necessity patients have to be accepted by the ones around them [25]. This may be a strategy developed to manipulate the information so that those who are closer to the patient will not present a negative reaction when in face of the disease [26].

Based on that, individual vulnerability can be highlighted and expressed in contexts like: family, affective-sexual and professional relations; friendship networks; health condition; personal history; cultural level; education background; access to information; values; beliefs; desires; emotions, attitudes, gestures, speeches and own interests [23]. All of these contexts could be observed in this discussion.

In sum, the denial of the disease by TB patients strengthens the individual vulnerability, making healing more and more difficult.

\section{Category 3 - Resistance to Treatment}

One of the managers considered the resistance to TB treatment as the major barrier to the healing of the disease:

...the most difficult barrier to overcome is the resistance patients show to start the medication treatment.

Other participants also considered resistance to the treatment as an obstacle to healing. They mentioned the reasons that justify such difficulty as seen below: 
....When it comes to accepting the treatment, people always think they will not heal. Despite all the efforts, they think the disease will only get worse...

...many don't want to take the medication because they fear something bad might happen to them, so they keep their distance from the treatment...

The second difficulty that comes up related to the regular treatment is the fact that they have to make concessions, give up of certain things they were used to before...

Tuberculosis treatment refusal and abandonment are associated with not only social, cultural and demographic barriers but also those involved in the production process of health services and problems with medications [27]. They encompass the aspects of individual, social and programmatic vulnerabilities that are directly interrelated, resulting in the gradual difficulty increase in terms of healing of the disease.

However, one of the main causes that makes TB be considered a major health issue is the incompleteness of the therapeutic scheme, with frequent abandonment of the treatment and the inadequate use of the medications, probably owing to the long-term administration and their adverse effects. The patient's clinical improvement during the first months of treatment, difficulties patients meet to be present at health units, denial of the disease and failures in the TB control program are also factors that illustrate this incompleteness [24].

Health professionals identify the stigma of the disease along with isolation and rejection factors included in the historical and social health-disease process of TB as other barriers to overcome [21].
To top it all off, physiopathological processes, HIV/AIDS co-infection, poor living conditions, cultural beliefs and pragmatic and structural failures in the health system organization are pointed as limiting factors to treatment adherence [21].

In relation to medication issues, associated adverse aspects [28] like taste, the intake amount and the size of the tablets pose as important risk factors for treatment abandonment. In general, all these factors represent a threat to a favorable TB outcome; therefore, efforts towards a multidisciplinary approach should be made in order to overcome the difficulties regarding medication adherence and tolerance in these patients [30].

Individual and programmatic vulnerabilities are highlighted here. Individual vulnerability is expressed by habits and personal behaviors; programmatic vulnerability is related to the evaluation of the following: programs developed to respond to disease control, the degree of commitment and quality control of the institutions, resources employed, management, and monitoring of the programs at different attention levels [31].

In this context, considering programmatic failures within this sphere and the feelings that arise when individuals face the disease, resistance to the treatment strengthens individual and programmatic vulnerabilities, resulting in difficulties that hinder the cure of TB patients.

\section{Category 4 - Lifestyle}

The lifestyle led by TB patients was also mentioned by managers as a hindrance to TB healing. Habits like alcoholism and smoking came up as seen in the statements below:

....another difficulty we face is their lifestyle, like the alcoholism problem patients have most of the time.

G-3 
Most of the patients are alcoholics. There are some who are also die-hard smokers, so the cure becomes even more difficult...

$\mathrm{G}-1$

....if they don't leave certain habits behind, like the drinking habit, it becomes very difficult for health professionals to treat these patients and find an ultimate cure...

Homelessness was another aspect related to lifestyle that was mentioned by one of the managers as transcribed below:

...homeless patients ... who live alone... it makes the adherence to treatment more difficult.

The manager also referred to this aspect of lifestyle as a barrier to the effectiveness of health educational programs:

.... all the information and guidance we provide concerning nutrition and rest periods go down the drain...

Many are the factors related to lifestyle that may partially explain non-adherence to TB treatment. Alcohol [29, 32-35] and drug [29, 30] abuse along with smoking $[3,33]$ figure high among these factors.

Besides being a hazard factor for treatment abandonment, alcoholism is also a clinical condition that poses as a potential risk for the development of the disease and the onset of adverse reactions. It also demands close attention from healthcare professionals since alcoholics are at high risk for toxicity [3].

The use of tobacco, in turn, has been not only widely accepted as a determinant factor for TB but also recognized as an obstacle for treatment adherence. Tobacco alters all defense mechanisms of the respiratory tree and increases the gravity of necrotizing lesions with probable extensive sequelae [3].

High rates of TB treatment dropout of homeless patients are related to low self-esteem, inadequate nutrition and issues inherent to the dynamics of the streets, which may involve theft of personal objects and/or the patient's removal from the streets along with their belongings by the social services department. As medication may be included in these belongings, the irregular intake of the drugs will interfere with the treatment outcome [36-38].

Therefore, the frequent TB treatment abandonment must be more carefully analyzed, and special attention should be devoted to special cases. Moreover, healthcare professionals need to be more involved in the process and adopt differentiated strategies owing to the transmission risk of the disease. Anti-TB chemoprophylaxis should be considered in these professionals, whenever applicable, as a form to lower their chances of getting sick.

In this category, when health information quality and level among patients come up along with measures to be taken, individual vulnerability approach is emphasized [31]. A lifestyle that includes habits like tobacco and alcohol consumption along with the homeless condition of a TB patient strengthens the individual vulnerability, making the obtainment of TB healing more difficult.

Although nowadays TB treatment is free of charge, easily accessible to all and effective in the great majority of the cases, a historical-social process inserts tuberculosis in a highly vulnerable scenario, in which individual, social and programmatic situations correlate among themselves, resulting in the incomplete effectiveness of actions.

Finally, TB diagnosed individuals live a situation of vulnerability characterized by social exclusion, low educational level, low-income status and a poverty situation. 
Health managers point to stigma, prejudice, denial of the disease, treatment resistance and habits like alcoholism and smoking as barriers to the control of tuberculosis in Cajazeiras, a municipality in the state of Paraíba, Brazil.

Upon establishing the relation between punctual aspects and the operationalization of actions, managers enter the inseparable three-dimensional universe of vulnerabilities: individual, social and programmatic.

Therefore, in order to obtain the cure of TB patients and the disease control, it is paramount to act on the elucidated aspects, not isolatedly, but in an interconnected way, so that situations of individual, social and programmatic vulnerabilities can be reverted.

\section{Final Consideration}

The findings in the current study reveal the vulnerability condition in which tuberculosis patients live, highlighting their social exclusion, their low educational level, their low-income status and the poverty situation they are faced with. Such factors hamper patients from visualizing their basic needs, like the importance of having a balanced diet in order to prevent or soothe the medication adverse effects they so often complain about.

The individual and social vulnerability aspects found here were poverty, low educational level and a per capita income lower than one minimum wage.

According to the perspective of patients, medication adverse effects, the lack of social-incentive schemes during the treatment and the long-term medication therapy were the major difficulties they faced to obtain the cure of tuberculosis.

Although healthcare managers pointed stigma, prejudice, denial of the disease with a resultant resistance to treatment, homelessness and drinking and smoking habits as major difficulties for tuberculosis control in the municipality, the capacity to relate these aspects to the implications in the execution of public policies and programmatic actions for tuberculosis control was highlighted.

Upon establishing the relation between punctual aspects and the operationalization of actions, managers enter the inseparable three-dimensional universe of vulnerabilities: individual, social and programmatic.

Therefore, in order to obtain the cure of TB patients and the disease control, it is paramount to act on the elucidated aspects, not isolatedly, but in an interconnected way, so that situations of individual, social and programmatic vulnerabilities can be reverted.

A better understanding of the real needs of tuberculosis patients as well as the prioritization of the disease are of utmost importance in the municipal public health agenda, which is based on a higher involvement of managers in the participation, discussion and definition of the application of resources for the disease control and a public health policy that encompasses tuberculosis social issues. 


\section{References}

1. Sánchez AIM, Bertolozzi MR. Operacionalização do conceito de vulnerabilidade à tuberculose em alunos universitários. Ciênc. saúde coletiva 2011; 16(2): 699-75.

2. Barbosa IR, Costa ÍCC. A Emergência da co-infecção tuberculose - HIV no Brasil. Hygeia 2012; 8(15): 232-44.

3. Ministério da Saúde (BR). Secretaria de Vigilância em Saúde. Departamento de Vigilância Epidemiológica: Manual de recomendações para o controle da tuberculose no Brasil. Brasília: Ministério da Saúde; 2011.

4. Piller RVB. Epidemiologia da Tuberculose. Pulmão RJ 2012; 21(1): 4-9.

5. Organização Mundial da Saúde: Global Tuberculosis Report; 2013 [acesso em 24 mai 2014]. Disponível em: apps.who.int/iris/ bitstream/10665/91355/1/9789241564656_eng.pdf.

6. Ministério da Saúde(BR). Secretaria de Vigilância em Saúde. Boletim Epidemiológico 2014; 44(2): 1-13.

7. Ministério da Saúde(BR). Sinan Net - Sistema de Informação de Agravos de Notificação; 2014 [acesso em 24 jun 2014] Disponível em: http://dtr2004.saude.gov.br/sinanweb/tabnet/dh?sinannet/ tuberculose/bases/tubercbrnet.def.

8. Ministério da Saúde (BR). Secretaria de Vigilância em Saúde. Departamento de Vigilância Epidemiológica. Manual de recomendações para o controle da tuberculose no Brasil/ Ministério da Saúde, Secretaria de Vigilância em Saúde, Departamento de Vigilância Epidemiológica. -Brasília: Ministério da Saúde; 2011.

9. Queiroz EM, Bertolozzi MR. Tuberculose: tratamento supervisionado nas Coordenadorias de Saúde Norte, Oeste e Leste do Município de São Paulo. Rev. Esc. Enferm. USP 2010; 44(2): 453-61.

10. Santos MLSG, Villa TCS, Vendramini SHF, Gonzáles RIC, Palha PF, Marin SNSG et al. A gerência das ações de controle da tuberculose em município prioritários do interior paulista. Texto \& contexto enferm. 2010; 19(1): 64-9.

11 Ferreira KR, Cavalcante EGR, De-La-Torre-Ugarte-Guanilo MC, Berti RAL, Bertolozzi MR. Portadores de tuberculose multirresistente em um Centro de Referência: perfil sóciodemográfico e clínico-epidemiológico. Rev. Esc. Enferm. USP 2011; 45(2): 1685-89.

12. Brunello MEF, Neto FC, Arcêncio RA, Andrade RLP, Magnabosco GT, Villa TCS. Áreas de vulnerabilidade para a coinfecção HIV/ aids/TB em Ribeirão Presto, SP. Rev Saúde Pública 2011; 45(3): 556-63.

13. Bertolozzi MR, Nichiata LYI, Takahashi RF, Ciosak SI, Hino P, Ferreira do Val $L$ et al. Os conceitos de vulnerabilidade e adesão na saúde coletiva. Rev. Esc. Enferm. USP 2009; 43(n.esp2): $1326-30$
14. Nichiata LYI, Bertolozzi MR, Gryschek ALPL, Araújo NVDL, Padoveze MC, Ciosak SI et al. Potencialidade do conceito de vulnerabilidade para a compreensão das doenças transmissíveis. Rev. Esc. Enferm. USP 2011; 45(2): 1769-73.

15. Ayres JRCM, Paiva V, França Junior I, Gravato N, Lacerda R, Negra MD et al. Vulnerability, human rights, and comprehensive health care needs of Young people living with HIVIAIDS. Am J Public Health 2006; 96 (6): 1001-6.

16. Bardin L. Análise de conteúdo. Lisboa: Edições 70; 2011.

17. Pôrto A. Representações sociais da tuberculose: estigma e preconceito. Rev Saúde Pública 2007; 41(Supl.1): 43-9.

18. World Health Organization.UNAIDS general populationsurvey. Geneva, Switzerland: WHO-UNAIDS; 2004. UNAIDS Global ReferenceGroupon HIVIAIDS and HumanRights 2004 [acesso em 15 jul 2014]. Disponível em: www.cpc.unc.edu/measure/ publications/unaids-00.17e/tools/unaidspopulation.html.

19. Cascais AFMV, Martini JG, Almeida PJS. Representações sociais sobre câncer. Rev. enferm. UERJ 2008; 16: 495-500.

20. Clementino FS, Martiniano MS, Clementino MJSM, Sousa JC, Marcolino EC, Miranda FAN. Tuberculose: desvendando conflitos pessoais e sociais. Rev. enferm. UERJ 2011; 19(4): 63843.

21. Muñoz SAl, Cruz MOA, Rubiano MYL. Trabajadores de lasalud y sus significados en torno a laadherencia al tratamiento de la tuberculosis. Enferm. glob. 2013; 12(31): 86-108.

22. Miranda FAN, Furegato ARF. A negação da sexualidade do doente mental. Rev enferm UERJ 2006; 14: 558-65.

23. Ayres JRCM, Paiva V, França Júnior I. Conceitos e práticas de prevenção: da história natural da doença ao quadro da vulnerabilidade e direitos humanos. In: Paiva, V, Ayres JR, Buchalla CM. Organizadores. Vulnerabilidade e direitos humanos: prevenção e promoção da saúde - livro I: da doença à cidadania. Curitiba: Juruá; 2012.

24. Oliveira HB, Moreira Filho DC. Abandono de tratamento e recidiva da tuberculose: aspectos de episódios prévios, Campinas, SP, Brasil, 1993-1994. Rev Saúde Pública 2000; 34(5): 437-43.

25. Souza SS, Silva DMGV, Meirelles BHS. Representações sociais sobre a tuberculose. Acta Paul Enferm 2010; 23(1): 23-8.

26. Ruffino-Netto A. Programa de controle da tuberculoseno Brasil: situação atual e novas perspectivas. InfEpidemiol SUS 2001; 10(3): 129-38.

27. Mishra P. Adherence to tuberculosis treatment under directly observed treatment, short-Course (DOTS) in Nepal: quantitative and qualitative studies [thesis]. Danish: The Danish University of Pharmaceutical Sciences; 2006.

28. Gonçalves H, Costa JSD, Menezes AMB, Knauth D, Leal OF. Adesão à terapêutica da tuberculose em Pelotas, Rio Grande do Sul: na perspectiva do paciente. Cad. Saúde Pública 1999; 15(4): 777-87. 
29. Paixão LMM, Gontijo ED. Perfil de casos de tuberculose notificados e fatores associados ao abandono, Belo Horizonte, MG. Rev Saúde Pública 2007; 41(2): 205-13.

30. Breen RA, Miller RF, Gorsuch T, Smith CJ, Schwenk A, Holmes W et al. Adverse events and treatment interruption in tuberculosis patientswith and without HIV co-infection. Thorax 2006; 61(9):791-94.

31. Ayres JRCM. Vulnerabilidade e AIDS: para uma resposta social à epidemia. Bol Epidemiol AIDS 1997; 15(3): 2-4

32. Natal S, Valente J, Gerhardt G, Penna ML. Modelo de predição para o abandono do tratamento da tuberculose pulmonar. Bol Pneumol Sanit. 1999; 7(1): 65-78.

33. Ribeiro AS, Amado VM, Camelier AA, Marcia MA, Fernandes MM, Schenkman S. Estudo caso-controle de indicadores de abandono em doentes com tuberculose. J Pneumol. 2000; 26(6): 291-6.

34. Bergel FS, Gouveia N: Frequent return as a novel strategy for tuberculosis treatment adherence. Rev Saude Publica 2005; 39(6): 898-905.

35. Campani STA, Moreira JS, Tietbohe CN. Fatores preditores para o abandono do tratamento da tuberculose pulmonar preconizado pelo Ministério da Saúde do Brasil na cidade de Porto Alegre (RS). J Bras Pneumol 2011; 37(6): 776-82.

36. Carbone MH. Tísica e rua: os dados da vida e seu jogo. 2000. 106 f. Dissertação [Mestrado em Endemias na área de Saúde Pública] -Escola Nacional de Saúde Pública, Fundação Oswaldo Cruz; 2000.

37. Centro de Referência Prof. Hélio Fraga CRPHF. Relatório da oficina Tuberculose nas Populações em Situação de Rua: Projeto Fortalecimento da Estratégia TS/DOTS em Grandes Centros Urbanos com Alta Carga de Tuberculose no Brasil. Brasilia; 2007.

38. Selig L, Guedes R, Kritski A, Spector N, Lapa e Silva JR, Braga $J U$ et al. Uses of tuberculosis mortality surveillance to identify programme errors and improve database reporting. Int J Tuberc Lung Dis. 2009; 13(8): 982-88.

\section{Comment on this article:}

\section{(f) (B) in $8+\mathcal{S}$}

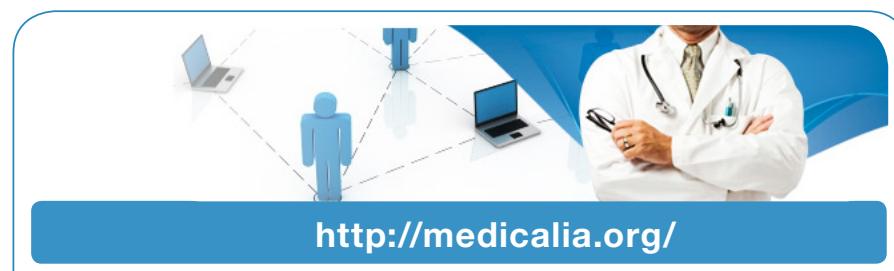

Where Doctors exchange clinical experiences, review their cases and share clinical knowledge. You can also access lots of medical publications for free. Join Now!

\section{Publish with iMedPub}

http://www.imed.pub

International Archives of Medicine is an open access journal publishing articles encompassing all aspects of medical science and clinical practice. IAM is considered a megajournal with independent sections on all areas of medicine. IAM is a really international journal with authors and board members from all around the world. The journal is widely indexed and classified Q1 in category Medicine. 